Research Article

\title{
The Prevalence of Cardiovascular Risk Factors among Polish Soldiers: The Results from the MIL-SCORE Program
}

\author{
Grzegorz Gielerak (iD, Paweł Krzesiński (D), Katarzyna Piotrowicz, Piotr Murawski, \\ Andrzej Skrobowski, Adam Stańczyk, Agata Galas, Beata Uziębło-Życzkowska (D), \\ Anna Kaźmierczak-Dziuk, Joanna Maksimczuk, Sylwia Miernik-Podleśko, \\ Monika Grzęda, Emilia Sopolińska, Marek Kiliszek (D), and Lidia Wojda
}

Department of Cardiology and Internal Medicine, Military Institute of Medicine, Warsaw, Poland

Correspondence should be addressed to Grzegorz Gielerak; ggielerak@wim.mil.pl and Marek Kiliszek; kiliszek@mp.pl

Received 6 December 2019; Revised 25 March 2020; Accepted 31 March 2020; Published 18 May 2020

Academic Editor: Frank Dini

Copyright ( $) 2020$ Grzegorz Gielerak et al. This is an open access article distributed under the Creative Commons Attribution License, which permits unrestricted use, distribution, and reproduction in any medium, provided the original work is properly cited.

\begin{abstract}
The MIL-SCORE (Equalization of Accessibility to Cardiology Prophylaxis and Care for Professional Soldiers) program was designed to assess the prevalence and management of cardiovascular risk factors in a population of Polish soldiers. We aimed to describe the prevalence of cardiovascular risk factors in the MIL-SCORE population with respect to age. This observational crosssectional study enrolled 6440 soldiers ( $97 \%$ male) who underwent a medical history, physical examination, and laboratory tests to assess cardiovascular risk. Almost half of the recruited soldiers were past or current smokers (46\%). A sedentary lifestyle was reported in almost one-third of those over 40 years of age. The prevalence of hypertension in a subgroup over 50 years of age was almost $45 \%$. However, the percentage of unsatisfactory blood pressure control was higher among soldiers below 40 years of age. The prevalence of overweight and obese soldiers increased with age and reached $58 \%$ and $27 \%$, respectively, in those over 50 years of age. Total cholesterol was increased in over one-half of subjects, and the prevalence of abnormal low-density lipoprotein cholesterol was even higher (60\%). Triglycerides were increased in 36\% of soldiers, and low high-density lipoprotein cholesterol and hyperglycemia were reported in $13 \%$ and $16 \%$ of soldiers, respectively. In the $>50$ years of age subgroup, high and very high cardiovascular risk scores were observed in almost one-third of soldiers. The relative risk assessed in younger subgroups was moderate or high. The results from the MIL-SCORE program suggest that Polish soldiers have multiple cardiovascular risk factors and mirror trends seen in the general population. Preventive programs aimed at early cardiovascular risk assessment and modification are strongly needed in this population.
\end{abstract}

\section{Introduction}

Despite the remarkable progress in diagnosis and treatment, cardiovascular diseases (CVDs) remain the leading cause of death in Europe [1]. One of the reasons for this issue is the rising prevalence of cardiovascular $(\mathrm{CV})$ risk factors, subclinical atherosclerosis, and minimal effectiveness of prevention programs [1]. The growing population of young and middle-aged patients presenting with increased CV risk is particularly distressing. The increasing number of individuals with obesity, unrecognized hypertension, and metabolic abnormalities poses a problem [1-3].
It is widely accepted that professional soldiers should not have CVDs. However, even when carefully selected in terms of exercise and general health, they are not free from CV risk factors. Webber et al. [4] showed a $12.1 \%$ prevalence of atherosclerosis (coronary or aortic) in a cross-sectional study conducted among United States military service members who died in combat operations $(n=3832$; mean age: 25.9 years; data from autopsy). In a study of 112 young Polish soldiers, Gielerak at al. [5] revealed that $\mathrm{CV}$ risk factors were present in over $50 \%$ of soldiers. Exposure to extensive stress and threats in combat conditions were suggested to have an additive detrimental effect [5]. 
Since most CV risk factors can be controlled, it is reasonable to focus on the identification of $\mathrm{CV}$ risk in a large population of Polish soldiers. For this reason, a preventive program for Polish armed forces personnel, the Equalization of Accessibility to Cardiology Prophylaxis and Care for Professional Soldiers, or MIL-SCORE, program was employed from 2013 to 2016 . We aimed to present its main results and reveal the prevalence of $\mathrm{CV}$ risk factors in a population of Polish soldiers with respect to age.

\section{Materials and Methods}

2.1. Study Protocol and Study Population. The MIL-SCORE program was designed to assess the prevalence and management of CV risk factors as well as to establish a CVD monitoring system in the Polish armed forces. The program was announced by a decision from the Polish Ministry of Military Defense (decision no. 15/MON; February 12, 2013) and included approximately $5 \%$ of all professional soldiers $(n=6440)$. The program was coordinated by the Military Institute of Medicine (Warsaw, Poland) in cooperation with three medical centers (the 5th Military Clinical Hospital with Polyclinic in Krakow; the 10th Military Clinical Hospital with Polyclinic in Bydgoszcz; the Military Specialist Medical Clinic in Legionowo). Between 2013 and 2016, medical teams that included cardiac nurses and cardiologists visited selected military units. Soldiers who were absent at the time of the visit were encouraged to report personally to the nearest recruitment center.

The study protocol included a face-to-face medical history, physical examination, and laboratory tests. All data were documented in a detailed questionnaire form. All patients gave written informed consent to participate in the study.

\subsection{Clinical Assessment}

2.2.1. Interview. Clinical assessment at the time of enrolment involved collection of the following sociodemographic data: age, gender, military rank, education level, and place of residence (i.e., countryside or town). The medical history focused on past and present chronic diseases including the following: hypertension (uncontrolled defined as a blood pressure (BP) $>135 / 85 \mathrm{mmHg}$ by out-of-office self-measurements), coronary artery disease, myocardial infarction, percutaneous transluminal coronary angioplasty, coronary artery bypass grafting, heart failure, peripheral arterial disease, chronic kidney disease, diabetes, and chronic obstructive pulmonary disease. A family history of CV risk factors and diseases was also investigated.

Physical activity was stratified as follows: (1) sedentary (i.e., sedentary lifestyle and occasional exercise), (2) moderate (i.e., regular vigorous activities less than $2.5 \mathrm{~h}$ per week), and (3) high (i.e., regular vigorous activities for more than $2.5 \mathrm{~h}$ per week). Smoking status categories were as follows: nonsmoker, former smoker, or current smoker.
2.2.2. Physical Examination. The following parameters were evaluated during physical examination: weight $(\mathrm{kg})$, height $(\mathrm{cm})$, and body mass index (BMI, calculated as the weight in kilograms divided by the square of the height in meters). The heart rate (HR) and office systolic blood pressure (SBP) and diastolic blood pressure (DBP) were measured in a quiet room in the presence of a trained physician or nurse following a minimum of $5 \mathrm{~min}$ of rest in a seated position. The category of hypertension was defined according to the European Society of Cardiology (ESC) guidelines [6].

2.2.3. Laboratory Tests. Blood samples were collected, and the concentrations of the following biochemical markers were determined using standard methods: total cholesterol (TC), triglycerides (TG), low-density lipoprotein cholesterol (LDL-C), high-density lipoprotein cholesterol (HDL-C), and glucose. All blood samples were processed at the field centers, immediately frozen, and transferred to the laboratories of the leading centers.

2.2.4. Cardiovascular Risk Assessment. The 10-year CV risk was calculated using the SCORE Risk Chart that was recalibrated for the Polish population (Pol-SCORE 2015) [7]. Individuals who scored $<1 \%$ were categorized as low risk; those who scored between $1 \%$ and $5 \%$ were categorized as moderate risk; those who scored between 5\% and $10 \%$ were categorized as high risk; those who scored $\geq 10 \%$ were categorized as very high risk. Relative risk charts were used for CV risk assessment in individuals aged 20-40 years [1]. Individuals with at least one of the following factors were categorized as high or very high CV risk: documented CVD history, diabetes (with the exception of young people with type 1 diabetes and without major risk factors), markedly elevated cholesterol ( $>310 \mathrm{mg} / \mathrm{dL})$ or BP $(>180 / 110 \mathrm{mmHg})$, or chronic kidney disease (eGFR $<60 \mathrm{~mL} / \mathrm{min} / 1.73 \mathrm{~m}^{2}$ ), according to European Guidelines on cardiovascular disease prevention [1].

2.3. Statistical Analysis. The quality of the data was critically evaluated, and data that were most likely erroneous were eliminated. In the final analysis, missing data for any variable did not exceed 5\%, which should be considered a limitation that did not significantly affect the results. The numbers of complete records of the analyzed parameters are given in the tables.

The distribution and normality of the data were assessed via visual inspection and the Kolmogorov-Smirnov test. Continuous variables were presented as means \pm standard deviations (SDs), and categorical variables were presented as absolute and relative frequencies (percentages). For comparative analysis, the study group was stratified by age as follows: 20 to 30 years $(n=2324) ; 31$ to 40 years $(n=2471) ; 41$ to 50 years $(n=1343)$; over 50 years $(n=302)$. These subgroups were compared with an ANOVA for continuous variables and the Chi-square test or Fisher's exact test for categorical variables. A two-tailed $p$ value of $<0.05$ was 
considered statistically significant. Statistical analyses were performed using Statistica 12.0 (StatSoft, Inc., Tulsa, USA).

\section{Results}

A total of 6440 soldiers (mean age $34.9 \pm 8.1$ years; $97 \%$ male) participated in the study (Table 1). They represented the whole range of military ranks, with a predominance of privates, corporals, and noncommissioned officers. More soldiers lived in towns than in the countryside, and this difference was more strongly pronounced in soldiers over 50 years of age. The majority graduated from at least a secondary school. Almost half of the soldiers were past or current smokers, and the proportion of those who quit smoking increased with age. Occasional physical activity was reported by $12 \%$ of soldiers under 40 years of age and approximately $30 \%$ of those over 40 years of age (Table 1 ).

There were significant differences in BP among the subgroups, which demonstrated higher BP values in older soldiers. Among the entire study population, $14 \%$ of soldiers reported a history of hypertension.

The prevalence of hypertension increased with age, up to $44 \%$ in soldiers over 50 years of age (Table 2). Well-controlled home BP measurements were reported by only $40 \%$ of soldiers. In over $50 \%$ of soldiers, BP was abnormally high when measured in the office, and $14 \%$ of the values corresponded to grade 2 or 3 hypertension. Furthermore, onethird of normotensive soldiers had a high normal BP. The number of soldiers with increased $\mathrm{BP}$ when measured in the office was particularly high among soldiers who reported a history of hypertension (86\%).

Over one-third of the total group was overweight. The prevalence of overweight and obese soldiers increased with age and reached $58 \%$ and $27 \%$, respectively, in those over 50 years of age. Coronary artery disease was noted in $3 \%$ of soldiers over 50 years of age and $<1 \%$ of younger soldiers. Diabetes affected $7 \%$ of the oldest soldiers and $3 \%$ of soldiers aged $40-50$ years. The prevalence of other reported chronic diseases was marginal $(<1 \%)$. The detailed results are presented in Table 2.

The detailed results of laboratory tests are presented in Table 3. TC was increased in over one-half of subjects. The proportion of those with abnormal LDL-C was even higher (60\%). These results were accompanied by increased TG in $36 \%$ of soldiers, low HDL-C in $13 \%$ of soldiers, and glucose $>100 \mathrm{mg} / \mathrm{dl}$ in $16 \%$ of soldiers. The prevalence of these disturbances increased with age, especially for LDL-C and glucose. Metabolic abnormalities and the high prevalence of hypertension were reflected in the results of CV risk assessment (Table 4). Out of a total of 5985 soldiers, those with a calculated CV risk of $3 \%(n=189)$ were automatically categorized as high or very high CV risk. The others, most of whom were 40-50 years of age, were classified as moderate $\mathrm{CV}$ risk. In a subgroup of soldiers $>50$ years of age, high and very high $\mathrm{CV}$ risk scores were designated for almost onethird of soldiers. The relative risk assessed in younger subgroups ( $<40$ years of age) was moderate or high.

Subanalysis of soldiers 20-30 years of age revealed that predominant office work (more than $75 \%$ of time spent at office) was not linked with any significant differences in cardiovascular risk factors compared with soldiers physically active at work. Major difference was in smoking habit, which was less prevalent in soldiers with predominant office work ( $23.2 \%$ vs. $33.9 \% ; p=0.01)$. The differences were seen in almost all cardiovascular risk factors when comparing soldiers exercising sporadically with soldiers regularly active (waist circumference, BMI, LDL and HDL cholesterol, blood pressure measurements, and less smoking). Interestingly, prevalence of hypertension was comparable in both groups ( 6.5 vs. $5.1 \%, p=0.38$ ).

Summary of the prevalence of the risk factors is shown on Figure 1.

\section{Discussion}

The results of this program indicate that the cardiovascular conditions of professional Polish soldiers are consistent with the unfavorable trends in the general population. The high prevalence of obesity, metabolic disorders, and abnormal blood pressure require special attention. The incidence of $\mathrm{CV}$ risk factors increases with age, and the synergistic effect of these risk factors translates into an alarming number of individuals at risk of atherosclerotic events.

The program included approximately $5 \%$ of all Polish professional soldiers, which were mainly men (97\%). The sample size was similar to that in the WOBASZ II study (6440 vs. 6163) [8]. Most of the soldiers were young (mean age 35 years), and only $26 \%$ reached the fifth and sixth decade of life. Although the number of current smokers decreased with age, a high percentage of smokers was observed (46\%). A negative age-related trend in physical activity was noted. Among soldiers over 40 years of age, almost $30 \%$ reported a sedentary lifestyle. Since smoking and physical inactivity are strong predictors of CV events [1], lifestyle modifications should be first-line treatment in this population.

The results of office BP measurements suggest a higher prevalence of hypertension than was reported by the soldiers. Only $32 \%$ of soldiers had an office BP $<130 / 80 \mathrm{mmHg}$; $16 \%$ had high normal values, and 52\% had hypertension ( $>140$ / $90 \mathrm{mmHg}$ ). In the WOBASZ II study [8], optimal BP was observed in $34.2 \%$ of men and $22 \%$ of those aged $19-49$ years. Compared with age-paired groups, the mean BP in the WOBASZ study was slightly lower than that in our study $[8,9]$.

In our study population, the number of soldiers with previously diagnosed hypertension increased with age. Less than half of hypertensive soldiers reported good BP control according to home BP measurements (39\%). The results of office measurements were even worse; no more than $14 \%$ of hypertensive soldiers had a BP $<140 / 90 \mathrm{mmHg}$. These observations are consistent with the NATPOL PLUS results, in which effective hypertensive treatment was noted in only $12 \%$ of participants [10]. In the WOBASZ II study, BP normalization was reported in $19 \%$ of men. The authors of the WOBASZ II study observed the worst pressure control in young participants (i.e., those aged 19-49 years) [8].

Most soldiers were overweight (55\%) or obese (14\%). The high prevalence of obesity correlated with an age-related 
TABLE 1: Sociodemographic data.

\begin{tabular}{|c|c|c|c|c|c|c|}
\hline & Total & $20-30$ years of age & $31-40$ years of age & $41-50$ years of age & $>50$ years of age & $p$ value \\
\hline Gender (male/female) ${ }^{6440}$ & $\begin{array}{l}6245 / 195 \\
(97.0 / 3.0)\end{array}$ & $2237 / 87(96.3 / 3.7)$ & $2384 / 87(96.5 / 3.5)$ & $1325 / 18(98.7 / 1 / 3)$ & $299 / 3(99.0 / 1.0)$ & 0.00003 \\
\hline Age (years) ${ }^{6440}$ & $34.9 \pm 8.1$ & $26.8 \pm 2.4$ & $35.2 \pm 2.9$ & $44.3 \pm 2.8$ & $54.0 \pm 3.1$ & \\
\hline $\begin{array}{l}\text { Residence } \\
{\text { (countryside/town })^{6169}}^{\text {Family history }^{6333}}\end{array}$ & $\begin{array}{l}1788 / 4381 \\
(30.0 / 70.0)\end{array}$ & $\begin{array}{c}798 / 1460 \\
(35.3 / 64.6)\end{array}$ & $\begin{array}{c}703 / 1692 \\
(29.4 / 70.6)\end{array}$ & $\begin{array}{l}252 / 1008 \\
(20.0 / 80.0)\end{array}$ & $\begin{array}{c}35 / 221 \\
(13.7 / 86.3)\end{array}$ & $<0.00001$ \\
\hline Coronary artery disease & $732(11.6)$ & $126(5.4)$ & $268(10.9)$ & $273(21.1)$ & 65 (24.4) & $<0.00001$ \\
\hline Hypertension & $1302(20.6)$ & $332(14.3)$ & $541(22.1)$ & $348(26.8)$ & $81(30.5)$ & $<0.00001$ \\
\hline Stroke & $275(4.3)$ & $46(2.0)$ & $112(4.6)$ & $90(6.9)$ & $27(10.2)$ & $<0.00001$ \\
\hline $\begin{array}{l}\text { Diabetes } \\
\text { Smoking status }\end{array}$ & $695(11.0)$ & $157(6.8)$ & $281(11.5)$ & $224(17.3)$ & $33(12.4)$ & $<0.00001$ \\
\hline Yes/current* & $\begin{array}{l}2933(46.2) / \\
1844(62.9)\end{array}$ & $\begin{array}{c}1069(46.8) / 772 \\
(72.2)\end{array}$ & $\begin{array}{c}1149(47.3) / 743 \\
(64.7)\end{array}$ & $\begin{array}{c}551(43.1) / 282 \\
(51.1)\end{array}$ & $\begin{array}{c}113(44.5) / 47 \\
(41.6)\end{array}$ & $\begin{array}{c}0.075 / \\
<0.00001\end{array}$ \\
\hline $\begin{array}{l}\text { Smoking: pack-years } \\
\text { (median, interquartile } \\
\text { range) } \\
\text { Physical activity } \\
6311\end{array}$ & $6(2.5-11.25)$ & $4(1.6-7.0)$ & $7(3.0-12.0)$ & $11(5.0-20.0)$ & $18.9(10.0-30.0)$ & $<0.0001$ \\
\hline Occasional & $1051(16.7)$ & $213(9.2)$ & $361(14.8)$ & $400(30.9)$ & $77(29.5)$ & \\
\hline Moderate & $2773(43.9)$ & $1307(56.5)$ & $1068(43.7)$ & $335(25.9)$ & $63(24.1)$ & $<0.00001$ \\
\hline High & $2487(39.4)$ & $793(34.3)$ & $1015(41.5)$ & $558(43.2)$ & $121(46.4)$ & \\
\hline
\end{tabular}

Data presented as mean \pm standard deviation $(\mathrm{SD})$ and number (percentage), respectively; *Among smokers responding yes.

TABLE 2: Basic clinical characteristics.

\begin{tabular}{|c|c|c|c|c|c|c|}
\hline & Total & $\begin{array}{c}20-30 \text { years of } \\
\text { age }\end{array}$ & $\begin{array}{c}31-40 \text { years of } \\
\text { age }\end{array}$ & $\begin{array}{c}41-50 \text { years of } \\
\text { age }\end{array}$ & $\begin{array}{c}>50 \text { years of } \\
\text { age }\end{array}$ & $p$ value \\
\hline HR (bpm) $)^{6311}$ & $73.7 \pm 11.8$ & $74.0 \pm 11.7$ & $73.9 \pm 12.0$ & $73.2 \pm 11.3$ & $72.2 \pm 12.2$ & 0.033 \\
\hline $\mathrm{SBP}(\mathrm{mmHg})^{6304}$ & $134.7 \pm 16.5$ & $132.7 \pm 15.8$ & $134.8 \pm 16.2$ & $137.7 \pm 17.6$ & $137.4 \pm 18.5$ & $<0.00001$ \\
\hline DBP $(\mathrm{mmHg})^{6304}$ & $83.1 \pm 11.4$ & $79.5 \pm 10.6$ & $83.6 \pm 10.8$ & $87.4 \pm 10.8$ & $88.0 \pm 12.4$ & $<0.00001$ \\
\hline $\mathrm{BP}=130-139 / 85-89(\mathrm{mmHg})^{6304}$ & $1006(16.0)$ & $358(15.5)$ & $378(15.5)$ & $225(17.4)$ & $45(17.1)$ & $<0.00001$ \\
\hline $\mathrm{BP}=140-159 / 90-99(\mathrm{mmHg})^{6304}$ & $2403(38.1)$ & $754(32.6)$ & $1003(41.1)$ & $535(41.4)$ & $111(42.2)$ & $<0.00001$ \\
\hline $\mathrm{BP}=160-179 / 100-109(\mathrm{mmHg})^{6304}$ & $708(11.2)$ & $163(7.0)$ & $268(11.0)$ & $222(17.2)$ & $55(20.9)$ & $<0.00001$ \\
\hline $\mathrm{BP}>180 / 110(\mathrm{mmHg})^{6304}$ & $158(2.5)$ & $27(1.2)$ & $55(2.2)$ & $63(4.9)$ & $13(4.9)$ & $<0.00001$ \\
\hline BMI $\left(\mathrm{kg} / \mathrm{m}^{2}\right)^{6316}$ & $26.7 \pm 3.3$ & $25.6 \pm 2.9$ & $26.8 \pm 3.1$ & $28.0 \pm 3.5$ & $28.2 \pm 3.3$ & $<0.00001$ \\
\hline Overweight (BMI $\left.25-29.9 \mathrm{~kg} / \mathrm{m}^{2}\right)^{6316}$ & $3447(54.6)$ & $1152(49.8)$ & $1407(57.5)$ & $735(56.9)$ & $153(58.2)$ & $<0.00001$ \\
\hline Obesity $\left(\mathrm{BMI} \geq 30.0 \mathrm{~kg} / \mathrm{m}^{2}\right)^{6316}$ & $893(14.1)$ & $157(6.8)$ & $345(14.1)$ & $320(24.8)$ & $71(27.0)$ & $<0.00001$ \\
\hline \multicolumn{7}{|l|}{ Chronic diseases in anamnesis ${ }^{633}$} \\
\hline Coronary artery disease & $14(0.2)$ & $0(0.0)$ & $0(0.0)$ & $5(0.4)$ & $9(3.4)$ & $<0.00001$ \\
\hline Myocardial infarction & $10(0.2)$ & $0(0.0)$ & $0(0.0)$ & $7(0.5)$ & $3(1.1)$ & $<0.00001$ \\
\hline Chronic kidney disease & $11(0.2)$ & $1(0.04)$ & $5(0.2)$ & $5(0.4)$ & $0(0.0)$ & 0.101 \\
\hline Diabetes mellitus & $63(1.0)$ & $0(0.0)$ & $6(0.24)$ & $39(3.0)$ & $18(6.8)$ & $<0.00001$ \\
\hline $\begin{array}{l}\text { Chronic obstructive pulmonary } \\
\text { disease }\end{array}$ & $10(0.2)$ & $0(0.0)$ & $4(0.2)$ & $4(0.3)$ & $2(0.8)$ & 0.009 \\
\hline Hypertension & $834(13.7)$ & $122(5.3)$ & $260(10.6)$ & $333(25.7)$ & $1119(44.7)$ & $<0.00001$ \\
\hline $\begin{array}{l}\text { Hypertension in medical history and } \\
\text { office } \mathrm{BP} \geq 140 / 90 \mathrm{mmHg}\end{array}$ & $717(86.0)$ & $90(73.8)$ & $237(91.1)$ & $292(88.0)$ & $98(82.4)$ & - \\
\hline $\begin{array}{l}\text { Declared well home BP control: } \\
\text { confirmed well BP control }\end{array}$ & $\begin{array}{c}293(38.7) / 465 \\
(61.3)\end{array}$ & $\begin{array}{c}24(23.8) / 77 \\
(76.2)\end{array}$ & $\begin{array}{c}67(28.3) / 170 \\
(71.7)\end{array}$ & $\begin{array}{c}145(47.2) / 162 \\
(52.8)\end{array}$ & $\begin{array}{c}57(50.4) / 56 \\
(49.6)\end{array}$ & $<0.00001$ \\
\hline
\end{tabular}

Data presented as mean \pm standard deviation $(\mathrm{SD})$ and number (percentage) ${ }^{*} p$ value not calculated (very low prevalence). BP: blood pressure; DBP: diastolic blood pressure; BMI: body mass index; HR: heart rate; SBP: systolic blood pressure.

negative trend in physical activity. Among young soldiers, only $10 \%$ were obese. However, less than $50 \%$ of them had a normal BMI. One-fourth of soldiers aged over 40 years had a $\mathrm{BMI}>30 \mathrm{~kg} / \mathrm{m} 2$. Abnormal weight was reported in $62 \%$ of participants in the WOBASZ study [8], and 53\% of participants in the NATPOL PLUS study [10].

Metabolic abnormalities were represented by high LDLC in $60 \%$ of soldiers, high TG in $36 \%$ of soldiers, and high TC in $52 \%$ of soldiers. These results are comparable with those in previous reports. Gielerak et al. [5] reported dyslipidemia in $51 \%$ of young (mean age $26.9 \pm 4.3$ years), healthy male soldiers $(n=112)$. Mazurek et al. [11] revealed hypercholesterolemia in $72.4 \%$ of 272 Polish military pilots. In a population of Polish professional drivers (96\% men, mean age 50 years, mean BMI $32 \mathrm{~kg} / \mathrm{m}^{2}$ ), Krzowski et al. [12] noted hypercholesterolemia in $50 \%$ of participants, high LDL-C in 
TABLE 3: The results of laboratory tests.

\begin{tabular}{|c|c|c|c|c|c|c|}
\hline & Total & $\begin{array}{l}20-30 \text { years of } \\
\text { age }\end{array}$ & $\begin{array}{l}31-40 \text { years of } \\
\text { age }\end{array}$ & $\begin{array}{l}41-50 \text { years of } \\
\text { age }\end{array}$ & $\begin{array}{l}>50 \text { years of } \\
\text { age }\end{array}$ & $p$ value \\
\hline Glucose $(\mathrm{mg} / \mathrm{dl})^{6255}$ & $88.8 \pm 23.2$ & $83.8 \pm 20.7$ & $88.3 \pm 17.3$ & $95.2 \pm 23.8$ & $106.1 \pm 53.7$ & $<0.00001$ \\
\hline TC $(\mathrm{mg} / \mathrm{dl})^{6440}$ & $197.5 \pm 42.0$ & $181.5 \pm 37.0$ & $202.0 \pm 39.2$ & $215.1 \pm 44.2$ & $211.4 \pm 48.4$ & $<0.00001$ \\
\hline TG (mg/dl) $)^{6285}$ & $152.0 \pm 121.3$ & $128.3 \pm 88.2$ & $158.7 \pm 117.9$ & $180.9 \pm 167.7$ & $156.5 \pm 91.6$ & $<0.00001$ \\
\hline LDL-C (mg/dl) $)^{6440}$ & $128.3 \pm 36.8$ & $114.6 \pm 32.2$ & $131.8 \pm 35.1$ & $144.3 \pm 38.5$ & $141.6 \pm 38.5$ & $<0.00001$ \\
\hline $\mathrm{HDL}-\mathrm{C}(\mathrm{mg} / \mathrm{dl})^{6262}$ & $52.7 \pm 12.7$ & $53.4 \pm 12.5$ & $52.7 \pm 13.0$ & $51.6 \pm 12.6$ & $52.0 \pm 11.5$ & 0.0007 \\
\hline Glucose $>100 \mathrm{mg} / \mathrm{dl}^{6255}$ & $993(15.9)$ & $189(8.3)$ & $366(15.0)$ & $322(25.2)$ & $116(45.3)$ & $<0.00001$ \\
\hline $\mathrm{T}-\mathrm{C}>190 \mathrm{mg} / \mathrm{dl}^{6440}$ & $3357(52.1)$ & $820(35.3)$ & $1430(57.9)$ & $937(69.8)$ & $170(56.3)$ & $<0.00001$ \\
\hline $\mathrm{LDL}-\mathrm{C}>115 \mathrm{mg} / \mathrm{dl}^{6245}$ & $3844(59.8)$ & $1064(46.1)$ & $1604(66.3)$ & $989(78.2)$ & $187(74.2)$ & $<0.00001$ \\
\hline $\mathrm{TG}>150 \mathrm{mg} / \mathrm{dl}^{6285}$ & $2274(36.2)$ & $606(26.3)$ & $955(39.1)$ & $608(47.4)$ & $105(40.7)$ & $<0.00001$ \\
\hline $\begin{array}{l}\text { HDL-C }<40 \mathrm{mg} / \mathrm{dl} \text { (men) and }<46 \mathrm{mg} / \\
\mathrm{dl} \text { (women) }\end{array}$ & $823(13.1)$ & $262(11.4)$ & $328(13.5)$ & $200(15.7)$ & $33(12.9)$ & 0.003 \\
\hline
\end{tabular}

Data presented as mean \pm standard deviation (SD) and number (percentage). HDL: high density lipoproteins cholesterol; LDL-C: low density lipoproteins cholesterol; TC: total cholesterol; TG: triglycerides.

TABle 4: Cardiovascular risk assessment and selected single risk factors by age.

\begin{tabular}{|c|c|c|c|c|c|c|}
\hline & Total & $20-30$ years of age & $31-40$ years of age & $41-50$ years of age & $>50$ years of age & $p$ value \\
\hline \multicolumn{7}{|l|}{ CV risk by SCORE ${ }^{5985}$} \\
\hline Mean SCORE & $2.4 \pm 1.5$ & $2.4 \pm 1.3$ & $2.7 \pm 1.5$ & $1.5 \pm 1.0$ & $4.3 \pm 2.5$ & $<0.00001$ \\
\hline SCORE $<1 \%$ & $9(0.2)^{*}$ & $0(0.0)^{*}$ & $0(0.0)$ & $9(0.8)$ & $0(0.0)$ & \multirow{4}{*}{$<0.00001$} \\
\hline SCORE $\geq 1$ and $<5 \%$ & $5479(91.5)^{*}$ & $2080(93.0)^{*}$ & $2091(89.5)$ & $1161(97.5)$ & $147(66.5)$ & \\
\hline SCORE $\geq 5 \%$ and $<10 \%$ & $472(7.9)^{*}$ & $155(6.9)^{*}$ & $237(10.2)$ & $18(1.5)$ & $62(28.1)$ & \\
\hline SCORE $\geq 10 \%$ & $25(0.4)^{*}$ & $2(0.1)^{*}$ & $8(0.3)$ & $3(0.3)$ & $12(5.4)$ & \\
\hline \multicolumn{7}{|c|}{ Prevalence of single clinical markers of high or very high $C V$ risk } \\
\hline $\mathrm{BP}>180 / 110 \mathrm{mmHg}^{6304}$ & $158(2.5)$ & $27(1.2)$ & $55(2.2)$ & $63(4.9)$ & $13(4.9)$ & $<0.00001$ \\
\hline $\mathrm{T}-\mathrm{C}>310 \mathrm{mg} / \mathrm{dl}^{6440}$ & $89(1.4)$ & $8(0.3)$ & $37(1.5)$ & $35(2.6)$ & $9(3.0)$ & $<0.00001$ \\
\hline Coronary artery disease ${ }^{6333}$ & $14(0.2)$ & $0(0.0)$ & $0(0.0)$ & $5(0.4)$ & $9(3.4)$ & $<0.00001$ \\
\hline Chronic kidney disease ${ }^{6333}$ & $11(0.2)$ & $1(0.04)$ & $5(0.2)$ & $5(0.4)$ & $0(0.0)$ & 0.101 \\
\hline Diabetes mellitus $^{6333}$ & $63(1.0)$ & $0(0.0)$ & $6(0.24)$ & $39(3.0)$ & $18(6.8)$ & $<0.00001$ \\
\hline
\end{tabular}

Data presented as number (percentage). ${ }^{*}$ Relative risk. BP: blood pressure; SCORE: systematic coronary risk evaluation.

$72 \%$ of participants, and high TG in $29 \%$ of participants. Only low HDL-C was significantly higher (84\%) than in our study group (13\%) [11]. In the NATPOL 2011 study [10], hypercholesterolemia was reported in $61 \%$ of participants, and hypertriglyceridemia was reported in $21 \%$ of participants. A slightly higher prevalence of dyslipidemia was reported in the WOBASZ study (69\% in women and $74 \%$ in men) $[9,13]$.

The prevalence of previously diagnosed diabetes in the entire study population was low (1\%). However, among soldiers over 50 years of age, its prevalence reached $7 \%$, which was similar to that of the general population [14]. The plasma glucose concentration exceeded $100 \mathrm{mg} / \mathrm{dl}$ in $16 \%$ of soldiers and almost half of soldiers over 50 years of age. Although nonfasting glucose measurements might overestimate the prevalence of increased plasma glucose concentrations, the true incidence of carbohydrate disorders should be verified more thoroughly.

Due to the aforementioned CV risk factor data, it is not surprising that the majority of subjects were categorized as moderate or high CV risk. The low prevalence of low CV risk $(n=9)$ among soldiers, a population that is expected to be notably healthy, is distressing.

A high prevalence of $\mathrm{CV}$ risk factors was also reported in the military personnel of other nations. O'Donnell et al. [15] performed an extensive analysis of the data from the Defense Medical Surveillance System records for 3,105,061 active duty soldiers who served in the United States Armed Forces at any time between 2007 and 2016. During that period, 18\% of all service members were diagnosed with at least one of the following CV risk factors: hypertension, hyperlipidemia, obesity, or abnormal blood glucose. In an age subgroup analysis, the prevalence of obesity increased with age and reached a rate of 23.5 per 1000 person-years in those aged over 50 years and 18.3 in those aged $20-29$ years. The same trend was observed for hyperlipidemia (80.6 versus 9.2, respectively), abnormal glucose levels (28.9 versus 2.0, respectively), and hypertension (54.4 versus 10.0, respectively). Therefore, many American soldiers have developed or have been discovered to have CV risk factors while in the military service despite being more physically active and in good physical health at the time of enlistment in the army. The CV risk factor prevalence is higher in military healthcare members than in those of other occupations.

Grosz et al. [16] reported a prevalence of $41 \%$ for obesity, $32 \%$ for smoking, $24 \%$ for physical inactivity, and $54 \%$ for hypercholesterolemia among 250 male Hungarian military pilots. The only significant difference from our population was the low incidence of hypertension (15\%). Among Lithuanian active duty military personnel $(n=200,126$ 


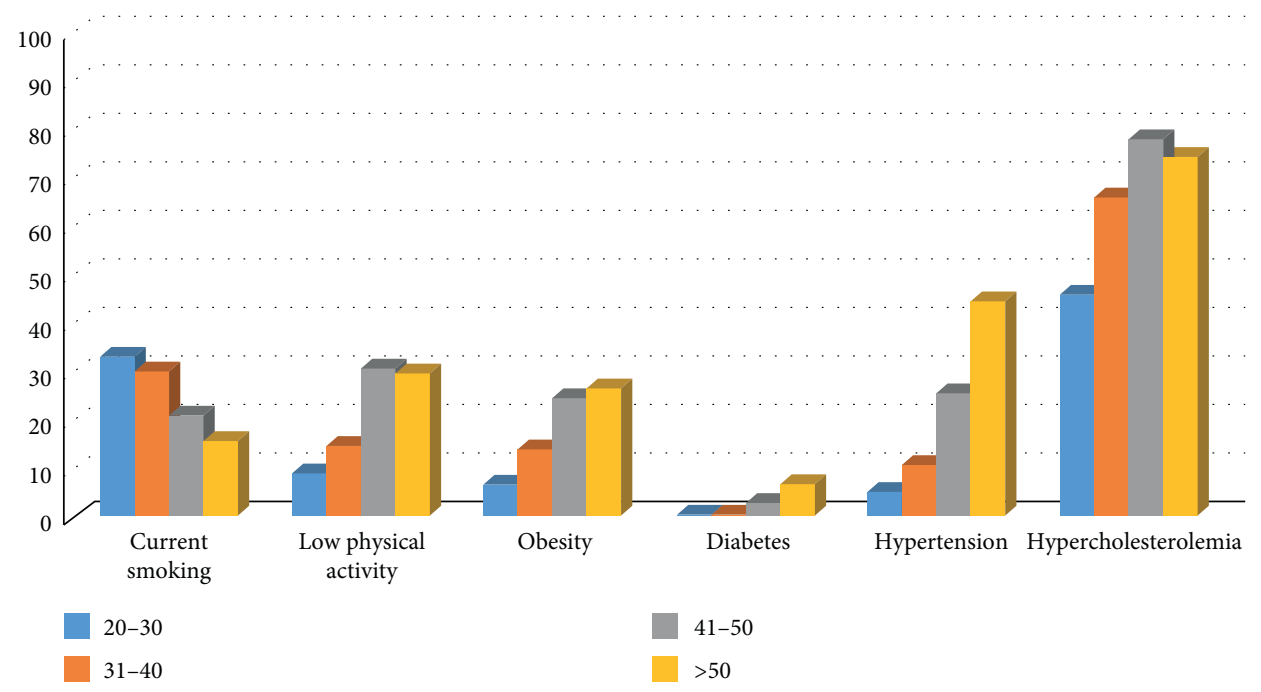

Figure 1: Distribution of risk factors divided by age (age groups: $20-30,31-40,41-50$ and $>50$ years of age). Scale on the left shows percentage of soldiers with risk factor. Obesity: BMI $>30 \mathrm{~kg} / \mathrm{m}^{2}$; hypercholesterolemia: LDL cholesterol $>115 \mathrm{mg} / \mathrm{dl}$.

men), hypercholesterolemia was discovered in $45 \%$ of the men, and its prevalence increased with age; in participants aged $45-54$ years, it was $74 \%$ [17]. The proportion of current male smokers was also high (46\%) and coexisted with metabolic disturbances [17]. In young male Brazilian military personnel ( $n=380$, aged $19-35$ years), Wenzel et al. [18] revealed that smoking was associated with the prevalence of hypertension $(22 \%)$, and a lack of regular physical activity was also associated with the prevalence of hypertension.

We demonstrated that in the 20-30 years of age group the absolute number of cardiovascular factors is very low. Hypertension was present in 5\% of soldiers, compared with about $10 \%$ of soldiers of that age in the American group. Diabetes was not prevalent in any of the group ( $0 \%$ of our group, $0.3 \%$ of American soldiers) [15]. The other authors have shown that among young adults aged $18-39$ years $8.8 \%$ had hypercholesterolemia and 7.3\% had hypertension [19]. Although we do not have data on the cardiovascular risk factors, it is worth to notice that severe coronary stenosis was found in about 15\% of soldiers who died in Korean war in autopsy studies and in 5\% of soldiers in autopsy studies of Vietnam war victims. In contemporary autopsy studies, the rate of severe atherosclerosis was $2.3 \%$ in soldiers predominantly below 30 years old [4]. The most probable reason for that decrease is a significant drop in smoking prevalence [1]although when looking at the trends over the last 40 years in the whole European population there is also a decrease in mean blood pressure and mean cholesterol level, but an increase in mean BMI and in prevalence of diabetes (data from 1980 to 2012-2015). [20].

Our results confirm that young adults who are physically active have less cardiovascular risk factors. The same was shown in Cardia study (young adults aged 18-30 years). Healthy lifestyle factors (i.e., not currently smoking, $\mathrm{BMI}<25$, and being on a healthy diet) were inversely related to total cholesterol, blood pressure, BMI, triglycerides, lipids, and fasting glucose [21]. This is consistent with cardiovascular prevention guidelines [1].
4.1. Clinical Implications. Due to the diagnosed health problems of Polish professional soldiers, it seems necessary to implement a comprehensive system that would include elements of effective prevention, diagnosis, and optimal treatment of CV risk factors. Such an adequate approach can reduce the likelihood of significant CVDs not only for those serving the military but also for those who have left the armed forces. Further research should focus on the identification of $\mathrm{CV}$ risk factors specific to military service personnel. Other occupational groups may also benefit from such an approach.

4.2. Limitations. One of the limitations is to some extent lack of originality of the results; there are publications showing distribution of the cardiovascular risk factors in different populations. The main limitation of our methodology was that the examined group included volunteers and was not a stratified random sample. Moreover, the population was dominated by men, which was due to the demographic structure of the Polish armed forces. BP measurement at only one visit might have resulted in the overestimation of hypertension prevalence. According to previous data, this overestimation affects $12.6 \%$ of participants [22]. Nonfasting laboratory tests also require caution in their interpretation. Detailed data concerning medications was not collected.

\section{Conclusions}

Soldiers are regarded as the epitome of health and fitness. However, findings from this study suggest that this occupational group does indeed have multiple CV risk factors and mirrors trends seen in the general population. Preventive programs aimed at early CV risk assessment and modification, including smoking cessation and management of hypertension and nutritional and metabolic disturbances, are strongly needed in this population. 


\section{Data Availability}

The data used to support the findings of this study are available from the corresponding author upon request.

\section{Conflicts of Interest}

The authors declare that there are no conflicts of interest regarding the publication of this paper.

\section{Acknowledgments}

The Equalization of Accessibility to Cardiology Prophylaxis and Care for Professional Soldiers, or MIL-SCORE program (or "wyrównanie dostępności do profilaktyk i opieki kardiologicznej dla żołnierzy zawodowych" in Polish), was founded by the Polish Ministry of Military Defense. The authors would like to express their gratitude to the personnel of all participating centers for their organizational efforts and data collection.

\section{References}

[1] M. F. Piepoli, A. W. Hoes, S. Agewall et al., "2016 European guidelines on cardiovascular disease prevention in clinical practice," European Heart Journal, vol. 37, no. 29, pp. 23152381, 2016.

[2] L. Fernández-Friera, J. L. Peñalvo, A. Fernández-Ortiz et al., "Prevalence, vascular distribution, and multiterritorial extent of subclinical atherosclerosis in a middle-aged cohort: the PESA (progression of early subclinical atherosclerosis) study," Circulation, vol. 131, no. 24, pp. 2104-2113, 2015.

[3] S. Yusuf, S. Hawken, S. Ônpuu et al., "Effect of potentially modifiable risk factors associated with myocardial infarction in 52 countries (the INTERHEART study): case-control study," The Lancet, vol. 364, no. 9438, pp. 937-952, 2004.

[4] B. J. Webber, P. G. Seguin, D. G. Burnett, L. L. Clark, and J. L. Otto, "Prevalence of and risk factors for autopsy-determined atherosclerosis among US service members, 20012011," JAMA, vol. 308, no. 24, pp. 2577-2583, 201226.

[5] G. Gielerak, P. Krzesiński, A. Stańczyk et al., "Cardiovascular risk factors among sol-diers-candidates for service abroad. The new perspective of epidemiological studies and prohealth behaviors in general population of the armed forces," Lek Wojsk, vol. 91, no. 4, pp. 387-394, 2013.

[6] B. Williams, G. Mancia, W. Spiering et al., "2018 ESC/ESH guidelines for the management of arterial hypertension," Eur Heart Journal, vol. 39, no. 33, pp. 3021-3104, 2018.

[7] https://www.ptkardio.pl/Uaktualniona_wersja_oceny_ ryzyka_sercowo_naczyniowego_Pol_SCORE_2015-2459.

[8] A. Niklas, A. Flotyńska, A. Puch-Walczak et al., "Prevalence, awareness, treatment and control of hypertension in the adult polish population-multi-center national population health examination surveys-WOBASZ studies," Archives of Medical Science, vol. 14, no. 5, pp. 951-961, 2018.

[9] G. Broda and S. Rywik, "Multicenter national Polish population health status tests-WOBASZ project with defined problems and treatment goals," Kardiologia Polska, vol. 63, pp. S601-S604, 2005.

[10] T. Zdrojewski, B. Solnica, B. Cybulska et al., "Prevalence of lipid abnormalities in Poland. The NATPOL 2011 survey," Kardiologia Polska, vol. 74, no. 3, pp. 213-223, 2016.
[11] K. Mazurek, A. Wielgosz, B. Efenberg, and A. Orzel, "Cardiovascular risk factors in superson-ic pilots in Poland," Aviation, Space, and Environmental Medicine, vol. 71, pp. 1202-1205, 2000.

[12] B. Krzowski, A. E. Płatek, F. M. Szymański et al., "Epidemiology of dyslipidemia in pro-fessional drivers: results of RACER-ABPM (risk of adverse cardiovascular events among professional drivers in Poland-ambulatory blood pressure monitoring) study," Kardiologia Polska, vol. 76, no. 2, pp. 396-400, 2018.

[13] G. Broda and S. Rywik, "Multicentre polish national trials on population health status-WOBASZ project. The definition, problem and main aims of the trial. Wieloośrodkowe ogólnopolskie badania zdrowia ludności-projekt WOBASZ," Kardiologia Polska, vol. 63, no. 4, pp. 601-604, 2005.

[14] M. Rutkowski, P. Bandosz, L. Czupryniak et al., "Prevalence of diabetes and impaired fasting glucose in Poland-the NATPOL 2011 study," Diabetic Medicine, vol. 31, no. 12, pp. 1568-1571, 2014.

[15] F. L. O'Donnell, S. Stahlman, and A. A. Oetting, "Incidence rates of diagnoses of cardiovascular diseases and associated risk factors, active component, U.S. armed forces, 2007-2016," MSMR, vol. 25, no. 3, pp. 12-18, 2018.

[16] A. Grósz, E. Tóth, and I. Péter, "A 10-year follow-up of ischemic heart disease risk factors in military pilots," Military Medicine, vol. 172, no. 2, pp. 214-219, 2007.

[17] R. Vaicaitiene, L. R. Cerniauskiene, D. I. Luksiene, and L. Margeviciene, "Hypercholesterolemia and smoking habits of Lithuanian military personnel," Military Medicine, vol. 171, no. 6, pp. 512-515, 2006.

[18] D. Wenzel, J. M. P. D. Souza, and S. B. D. Souza, "Prevalence of arterial hypertension in young military personnel and associated factors," Revista de Saúde Pública, vol. 43, no. 5, pp. 789-795, 2009.

[19] E. M. Bucholz, H. C. Gooding, and S. D. de Ferranti, "Awareness of cardiovascular risk factors in U.S. young adults aged 18-39 years," American Journal of Preventive Medicine, vol. 54, no. 4, pp. e67-e77, 2018.

[20] E. Wilkins, L. Wilson, K. Wickramasinghe et al., European Cardiovascular Disease Statistics 2017, European Heart Network, Brussels, Belgium, 2017.

[21] B. Spring, A. C. Moller, L. A. Colangelo et al., "Healthy lifestyle change and subclinical atherosclerosis in young adults: coronary artery risk development in young adults (CARDIA) study," Circulation, vol. 130, no. 1, pp. 10-17, 2014.

[22] D. Figueiredo, A. Azevedo, M. Pereira, and H. de Barros, "Definition of hypertension: the impact of number of visits for blood pressure measurement," Revista Portuguesa de Cardiologia, vol. 28, pp. 775-783, 2009. 